TI 2000-077/3

Tinbergen Institute Discussion Paper

\title{
Externalities in Urban Sustainability
}

Erik T. Verhoef

Peter Nijkamp 
Tinbergen Institute

The Tinbergen Institute is the institute for economic research of the Erasmus Universiteit Rotterdam, Universiteit van Amsterdam and

Vrije Universiteit Amsterdam.

Tinbergen I nstitute Amsterdam

Keizersgracht 482

1017 EG Amsterdam

The Netherlands

Tel.: +31.(0)20.5513500

Fax: $\quad+31 .(0) 20.5513555$

Tinbergen I nstitute Rotterdam

Burg. Oudlaan 50

3062 PA Rotterdam

The Netherlands

Tel.: $\quad+31 .(0) 10.4088900$

Fax: $\quad+31 .(0) 10.4089031$

Most TI discussion papers can be downloaded at

http://www.tinbergen.nl 


\title{
EXTERNALITIES IN URBAN SUSTAINABILITY
}

\section{Environmental versus agglomeration externalities in a general spatial equilibrium model of a single-sector monocentric industrial city}

\author{
Erik T. Verhoef ${ }^{*}$ and Peter Nijkamp ${ }^{*}$ \\ Department of Spatial Economics \\ Free University Amsterdam \\ De Boelelaan 1105 \\ 1081 HV Amsterdam \\ The Netherlands \\ Phone: +31-20-4446094 \\ Fax: +31-20-4446004 \\ Email: everhoef@econ.vu.nl
}

This version: $16 / 05 / 00$

Key words: Urban equilibrium, environmental externalities, agglomeration externalities

JEL codes: D62, R13, R14

\begin{abstract}
This paper studies urban sustainability from the perspective of externalities. We develop a general spatial equilibrium model of a monocentric city, in which two types of externalities occur. On the one hand, pollution in the industrial centre leads to a spatially differentiated deterioration of the environmental quality in the residential area. On the other hand, the existence of the city is explained by agglomeration economies, represented as simple Marshallian external benefits in production. We investigate free-market versus first-best and second-best optimal spatial equilibria, and conclude that the pursuit of environmental goals may sometimes come at the expense of reduced agglomeration economies, but may actually sometimes also stimulate these economies.
\end{abstract}

*Both authors are affiliated to the Tinbergen Institute, Keizersgracht 482, 1017 EG Amsterdam. The research of Erik Verhoef has been made possible by a fellowship of the Royal Netherlands Academy of Arts and Sciences. 


\section{Introduction}

The modern economic world is prominently shaped by an urban force field (Glaeser, 1998; Camagni et al., 1998; Abdel-Rahman, 1988). Cities often exhibit a wide array of attractive and unattractive features, and are hence governed by centripetal and centrifugal forces. Whereas, for instance, a rich cultural life or proximity to a wide variety of goods and services as well as to jobs may make a city an attractive location for living, countervailing negative consequences of an urban way of life may include noise and smell, higher criminality rates, smaller and more expensive housing, and a generally lower environmental quality than many rural locations would offer. Although in the long run market forces may be expected to lead to some equilibrium between positive and negative aspects of city life, it is doubtful whether the resulting geographical configuration would represent an efficient spatial-economic equilibrium. Many of the said positive and negative features of city life involve externalities: unpriced effects that economic agents impose upon one another. Free markets involving externalities typically do not yield the most efficient outcome. And this may have serious implications for the city.

In this paper, we aim to study the interaction between two types of externalities that seem particularly important in cities. The first of these is environmental pollution from industrial activities, leading to a decay in living conditions. The second concerns agglomeration externalities, in our study interpreted as economics of density in production. Agglomeration externalities are among the prominent economic reasons that may explain the sheer existence of cities. ${ }^{1}$ In particular - especially in case of competitive industries - producers would otherwise often have an incentive to locate outside a city, where labour and land are relatively cheap. This paper thus focuses on the possible trade-offs that may have to be made in urban policy making when care for the environmental quality in the urban area would call for a limitation of economic activity, while the optimal exploitation of agglomeration economies may require the opposite.

We will develop an admittedly simple model, which, however, captures the most important economic forces in a consistent framework. The main features of the model are the following. First of all, we consider a general spatial economic equilibrium. The land market, the labour market and the market for the industrial product in the city are simultaneously in equilibrium. Although we have a 'closed city', with a given population, labour supply is flexible and endogenous because a household can vary the hours of labour supplied. The firms are assumed to cluster in a spaceless 'CID' (Central Industrial District), and combine labour and a polluting input - energy - in their production process. The perfectly competitive firms have identical CES-production functions, implying that input substitution is possible. Agglomeration economies in the city are represented by 'Marshallian' externalities. We distinguish between two types of Marshallian externalities, one in which production efficiency increases with the

\footnotetext{
${ }^{1}$ External scale economies are called economies of localization if they occur between firms in the same industry, and economies of urbanization when occurring across industries (Anas et al., 1998). Considering a single-sector economy, this paper is confined to the former type.
} 
CID's total output, and one in which it increases with the CID's total labour force. Furthermore, the pollution is assumed to affect the local environmental quality in a spatially differentiated manner, according to a simple distance-decay function. Therefore, proximity to the CID yields a benefit in terms of relatively low commuting costs, and a disbenefit due to a relatively poor environmental quality. We aim to investigate the market equilibrium that results in such a configuration, and compare it with equilibria that would arise under various policies: an environmental tax in isolation, and in combination with a subsidy on external agglomeration benefits.

This paper fits in a tradition of research concerning the spatial implications of externalities in an urban context. Some classic examples include: Solow and Vickrey (1971), Oron et al. (1973) and Kanemoto (1976) on traffic congestion; Rose-Ackerman (1975), Kishimoto (1991) and Yinger (1992) on racism and segregation; Tiebout (1956) and Hamilton (1975) on local public goods; and Richardson (1977) and Tauchen (1981) on crowding externalities. Despite the fact that most modern cities have a polycentric structure (Anas et al., 1998, Giuliano and Small, 1991), these studies often use a monocentric configuration. An important justification is that a monocentric setting allows the identification of the most relevant economic phenomena while keeping the analysis tractable. Indeed, when there is no reason to expect a strong systematic effect of multiple centres upon the topic of study, or at least when such effects are not the primary topic of research, monocentric analyses can be expected to yield insights that carry over to more sophisticated polycentric configurations.

Although the literature on spatial (economic) aspects of environmental quality is large and growing (Nijkamp, 1999), the impacts of environmental pollution in the standard monocentric urban economic model seems to have received little attention. A number of hedonic price studies (see Freeman, 1993, for an overview) have tried to assess the onedirectional impact of environmental quality on housing prices, but an analysis of the full effects of environmental pollution in a general urban equilibrium setting, focussing also on the interaction between agglomeration and environmental externalities and taking into account all mutual interactions between production, environmental quality, the location of households and labour supply, has - to best of our knowledge - not been made to date.

The following section presents the full analytical details of this simplified model. Section 3 then proceeds by presenting the results of an illustrative numerical simulation model, and discusses the comparative static properties of the free market, first-best, and second-best equilibria. Section 4 concludes.

\section{Structure of the model}

\subsection{Introduction}

In this section, we present the details of the analytical model underlying our study. Section 2.2 discusses consumers' behaviour, Section 2.3 proceeds with the firms, and Section 2.4 concludes with a characterization of general equilibrium in the city.

Some introductory remarks are in order. First, $\mathrm{z}$ will be used to denote a onedimensional continuous urban space. The location of the spaceless industrial area is at $\mathrm{z}=0$, and 
the residential area stretches from $\mathrm{z}=0$ to $\mathrm{z}=\mathrm{z}^{*}$, with $\mathrm{z}^{*}$ being the endogenous city boundary. Commuting time increases linearly with $\mathrm{z}$ : there is no traffic congestion. At the boundary, the equilibrium residential bid-rent must be equalized to the exogenous and constant agricultural bid-rent $r_{A}$, following the standard rule that in an equilibrium situation, land should go to the highest bidder. In equilibrium, no household would have an incentive to move beyond $\mathrm{z}^{*}$, as it would increase commuting costs without reducing land-rent.

It is assumed that all excess land rents above $r_{A}$ are redistributed among the city's population. Alternatively, we could have used the 'absentee land-lord assumption', which as such would leave the qualitative conclusions unaltered, but would seem less realistic as it assumes that none of the land rents generated in the city would be used for consumption in the city. On the other hand, it is less plausible to assume that all land rents generated in the city are redistributed among the population, as this would imply that the endogenous city size could be expanded costlessly. The present representation would correspond to the situation where the public authority of the city buys the urban land against the relatively low rural land price, implying an equivalent per-unit-of time price of $r_{A}$, and redistributes all excess rents generated in the city among its population. It is a convenient assumption in the sense that it easily allows us to consider households with similar initial endowments. If residential land were privately owned, someone paying a high rent would at the same time receive that high rent, leaving him no worse off in budgetary terms than someone paying a low rent. A comparable assumption will be made with regard to the purchase of the polluting non-labour input in the production process, energy. Like land, also energy is bought against a given price on an open 'world market'. Some share of the urban production will therefore not be consumed in the urban area, but will be exported in exchange for the energy input and for the purchase of land against the agricultural rent.

Some final assumptions and remarks are to be made. All consumers and producers are assumed to be price-takers. Households are identical, and so are firms. The industrial product can be transported costlessly. The price of the industrial good can be used as the numéraire. However, since also the 'terms of trade' for agricultural land and the energy input are assumed to be exogenous, three prices can be set beforehand. We will now turn to the various actors in the city and the resulting equilibrium issues.

\subsection{Consumers}

The closed city has $\mathrm{N}$ households, which we will treat as a continuum of single economic entities. A household's utility depends on the consumption of the industrial good, y, on the consumption of space or the size of the residence, $s$, on the consumption of free time or leisure, $\mathrm{T}_{\mathrm{f}}$, and on the environmental quality, Eq. A household's financial budget consists of the wage rate times the amount of hours worked, plus the redistributed excess land rents. In equilibrium, this budget is fully spent on the consumption of $y$ and s. A household's given time budget is denoted by $T$, and can be spent on leisure $\left(T_{f}\right)$, work $\left(T_{w}\right)$ and commuting $\left(T_{c}\right)$. All prices are treated parametrically by the (price-taking) households; $w$ denotes the wage rate, $p$ the price of the industrial good, and $r$ the rent. Commuting does not require financial outlays, 
but costs time at a given rate $\mathrm{t}: \mathrm{T}_{\mathrm{c}}=\mathrm{t} \cdot \mathrm{z}$. A household's simultaneous labour supply and consumption decisions can be modelled by using the 'gross budget', that would be available under the maximum possible number of hours worked, and to let the household 'buy back' leisure time against the prevailing wage rate w. Observing that the household's optimization problem is dependent on the residential location $\mathrm{z}$, it can then be written:

$\underset{y(z), s(z), T_{f}(z)}{\operatorname{Max}} U\left(y(z), s(z), T_{f}(z), E q(z)\right)$
s.t. $\frac{R}{N}+w \cdot\left(T-t \cdot z-T_{f}(z)\right)-p \cdot y(z)-r(z) \cdot s(z)=0$

with:

$R=\int_{0}^{z^{*}} r(z)-r_{A} d z$

The gross budget available at location $\mathrm{z}$ is thus defined as:

$M(z)=\frac{R}{N}+w \cdot(T-t \cdot z)$

A spatial equilibrium requires that $\mathrm{U}(\mathrm{z})$ be constant over $\mathrm{z}$ for all $0<\mathrm{z} \leq \mathrm{z}^{*}$ (and exceeds $\mathrm{U}(\mathrm{z}$ ) for $\left.\mathrm{z}>\mathrm{z}^{*}\right)$ : if a higher utility could be reached at any $\mathrm{z}$, the rent $\mathrm{r}(\mathrm{z})$ would be bidden up, as households would like to move from their original location to $\mathrm{z}$ in order to enjoy the higher utility level prevailing there. Given the structure of the utility function and the pattern of $\mathrm{Eq}(\mathrm{z})$, this implies a particular equilibrium pattern of land-rents. We can be more explicit about this when postulating a specific form for the utility function. For instance, in the numerical model, we will be using a simple Cobb-Douglas structure:

$U(z)=y(z)^{\alpha_{y}} \cdot s(z)^{\alpha_{s}} \cdot T_{f}(z)^{\alpha_{f}} \cdot E q(z)^{\alpha_{e}}$

with : $\alpha_{y}+\alpha_{s}+\alpha_{f}=1$

Because utility is ordinal and any monotonous transformation of a given utility function represents the same preferences, the constraint on the parameters can be added without loss of generality. This utility function has the specific property of a unitary elasticity of substitution, implying that the gross income shares spent on $\mathrm{y}, \mathrm{s}$ and $\mathrm{T}_{\mathrm{f}}$ will be constant and given by the relative sizes of the parameters $\alpha$. More specifically, the conditional demands for $y, s$ and $T_{f}$ are:

$y(z)=\frac{\alpha_{y} \cdot M(z)}{p}$
$s(z)=\frac{\alpha_{s} \cdot M(z)}{r(z)}$
$T_{f}(z)=\frac{\alpha_{f} \cdot M(z)}{w}$

and the indirect utility - the maximum utility achievable under given prices and wage - can be written as: 


$$
\begin{aligned}
V(z) & =\alpha_{y} \cdot \ln \alpha_{y}+\alpha_{s} \cdot \ln \alpha_{s}+\alpha_{f} \cdot \ln \alpha_{f}+\ln \left(\frac{R}{N}+w \cdot(T-t \cdot z)\right) \\
& -\alpha_{y} \cdot \ln p-\alpha_{s} \cdot \ln r(z)-\alpha_{f} \cdot \ln w+\alpha_{e} \cdot \ln E q(z)
\end{aligned}
$$

(the Appendix provides a full derivation). $\mathrm{V}$ is, ceteris paribus, decreasing in $\mathrm{p}$ and $\mathrm{r}$, and increasing in Eq, which is all conform prior expectation. The effect of a ceteris paribus change in $\mathrm{w}$ is somewhat more difficult to derive. The partial derivative of $\mathrm{V}$ with respect to $\mathrm{w}$ is:

$$
\frac{\partial V(z)}{\partial w}=\frac{T-t \cdot z}{\frac{R}{N}+w \cdot(T-t \cdot z)}-\frac{\alpha_{f}}{w}
$$

(recall that, in general, $\operatorname{dln}(\mathrm{f}(\mathrm{x})) / \mathrm{dx}=\mathrm{f}^{\prime}(\mathrm{x}) / \mathrm{f}(\mathrm{x})$ ). Multiplying both terms on the right-hand side with $\mathrm{M}(\mathrm{z})$ as defined in (3), and using (5c), we can derive that (7) is greater than zero if:

$T-t \cdot z>T_{f} \Rightarrow T_{f}+T_{w}>T_{f}$

In other words, when labour supply is positive, a ceteris paribus increase in the wage rate always leads to a higher utility level.

Another noteworthy feature of this utility structure concerns the implied shape of the labour supply function. Any increase in the wage rate will lead to proportional increases in the consumption of $\mathrm{y}$ and $\mathrm{s}$. However, it would leave labour supplied unaffected if $\mathrm{R} / \mathrm{N}=0$ (there is no income other than through labour), and would lead to an increase in labour supply if $\mathrm{R} / \mathrm{N}>0$. This all follows from the partial derivatives of (5a-c) with respect to w:

$$
\begin{aligned}
& \frac{\partial y(z)}{\partial w}=\frac{\alpha_{y} \cdot(T-t \cdot z)}{p}>0 \\
& \frac{\partial s(z)}{\partial w}=\frac{\alpha_{s} \cdot(T-t \cdot z)}{r(z)}>0 \\
& \frac{\partial T_{f}(z)}{\partial w}=-\frac{\alpha_{f} \cdot R}{N \cdot w^{2}} \leq 0 \Rightarrow \frac{\partial T_{w}(z)}{\partial w} \geq 0
\end{aligned}
$$

Therefore, with $\mathrm{R} / \mathrm{N}=0$, the positive effect of $\mathrm{w}$ on $\mathrm{T}_{\mathrm{w}}$ (to supply more labour because the wage rate has increased) would exactly off-set the negative effect (to demand more leisure because the gross budget has increased). With $\mathrm{R} / \mathrm{N}=0$, (3) and (5c) immediately imply that a fixed share $\alpha_{\mathrm{f}}$ (independent of $\mathrm{w}$ ) of the total time available will be allocated to leisure. As (9c) shows, this property changes when also non-labour income is enjoyed. In our model, non-wage income is positive, and labour supply increases when the wage increases. Labour supply is furthermore endogenous because the location $\mathrm{z}$ is, implying that the time budget after commuting $(\mathrm{T}-\mathrm{t} \cdot \mathrm{z})$ is endogenous, too.

After this short discussion of some of the properties of a Cobb-Douglas utility function with endogenous labour supply, we now return to the spatial equilibrium. The condition that $\mathrm{V}$ in (6) be constant over place implies:

$$
V^{\prime}(z)=\frac{-w \cdot t}{\frac{R}{N}+w \cdot(T-t \cdot z)}-\alpha_{s} \cdot \frac{r^{\prime}(z)}{r(z)}+\alpha_{e} \cdot \frac{E q^{\prime}(z)}{E q(z)}=0
$$


where a prime denotes a space derivative. Equation (10) gives a first-order differential equation for $\mathrm{r}(\mathrm{z})$, which can be solved to yield:

$r(z)=\left(\frac{\left(\frac{R}{N}+w \cdot(T-t \cdot z)\right) \cdot E q(z)^{\alpha_{e}}}{K}\right)^{\frac{1}{\alpha_{s}}}$

(see the Appendix) where $\mathrm{K}$ is a constant of integration. Invoking the equilibrium condition that $\mathrm{r}\left(\mathrm{z}^{*}\right)=\mathrm{r}_{\mathrm{A}}$, we can solve for $\mathrm{K}$ :

$K=\frac{\left(\frac{R}{N}+w \cdot\left(T-t \cdot z^{*}\right)\right) \cdot E q\left(z^{*}\right)^{\alpha_{e}}}{r_{A}^{\alpha_{s}}}$

Equation (11) shows that (and how) $\mathrm{r}(\mathrm{z}$ ) should decrease with commuting costs and increase with environmental quality if utility is to be constant over place.

To derive the equilibrium level of utility, we must be explicit about the production structure. That issue will be treated in the next sub-section. We conclude this analysis with a few identities. First, we can find the population density as the inverse of the 'lot-size':

$n(z)=\frac{1}{s(z)}$

The total population is given, so that:

$\int_{0}^{z^{*}} n(z) d z=\int_{0}^{z^{*}} \frac{1}{s(z)} d z=N$

Total labour supplied equals:

$L=\int_{0}^{z^{*}} n(z) \cdot\left(T-t \cdot z-T_{f}(z)\right) d z$

Total consumption of the industrial product equals:

$Y=\int_{0}^{z^{*}} n(z) \cdot y(z) d z$

The total amount of land consumed in the city must be equal to $\mathrm{z}^{*}$, which is by definition true:

$z^{*}=\int_{0}^{z^{*}} n(z) \cdot s(z) d z=\int_{0}^{z^{*}} 1 d z=z^{*}$

Finally, we define environmental quality such that a virgin state corresponds to Eq=1, while the worst possible state, where an increase of consumption of other goods cannot even increase utility, occurs when Eq=0. Denoting the environmental emissions at the CID as E, which is also scaled so as to guarantee that $0 \leq \mathrm{E} \leq 1$, a spatially differentiated externality can be represented by letting $\mathrm{Eq}(\mathrm{z})$ be a decreasing function of $\mathrm{E}$ and an increasing function of $\mathrm{z}$. We will be using the following type of relation:

$E q=1-E \cdot e^{-a \cdot z}$

We thus assume an exponential distance-decay relation, with $a$ denoting the rate of decay. 


\subsection{Firms}

There is a continuum of firms, each of which is infinitesimally small relative to the market and takes all prices as given. The industrial output is homogeneous, and agglomeration externalities in our model thus arise from a more efficient production when the scale of production, or the size of the labour force, increases (see below). These agglomeration effects are summarized in an efficiency measure A, which individual firms take as given, but that is endogenous on the city level to represent agglomeration economics. Firms have a CES production technology with two inputs (labour and energy), which allows us to consider input substitution. A firm's production function is assumed to exhibit constant returns to scale, and therefore qualifies for application of Euler's theorem. Therefore, also when the urban aggregate production function exhibits increasing returns to scale due to agglomeration externalities, we can model the firms' behaviour using a 'derived aggregate production function', in which the efficiency parameter A is treated parametrically. The following derived aggregate production function applies:

$Q=A \cdot\left(\left(\delta_{L} \cdot L\right)^{\rho}+\left(\delta_{E} \cdot E n\right)^{\rho}\right)^{\frac{1}{\rho}}$

where $\mathrm{L}$ is the aggregate labour input, $\mathrm{En}$ is the aggregate energy input, $\delta_{\mathrm{L}}$ and $\delta_{\mathrm{E}}$ and $\rho$ are parameters, where $\rho(\rho \neq 0 \leq 1)$ defines the elasticity of substitution $\sigma$ according to $\sigma=1 /(1-\rho)$. In particular, $\rho=-\infty$ corresponds to a Leontief production function, $\rho=1$ to a linear production function, and the limit of $\rho \rightarrow 0$ would reproduce a Cobb-Douglas production function. A convenient parameter often used when working with CES production functions is $r=\rho /(\rho-1)$, which we too will be using below.

One can imagine two distinctly different types of agglomeration economies. The first would be the situation where production efficiency, as represented by the variable A, increases with the size of the total production in the CID, Q. Agglomeration economies then reflect some purely localized form of 'learning by doing': the higher the CID's output, the more efficiently both inputs are used. We will call this 'Type Q agglomeration economies'. Alternatively, production efficiency could increase with an increase in the labour supply as given by the total number of hours worked in the CID, L. This could reflect the situation that with a larger size of the total labour input, the possibilities for efficiency gains due to a further division of labour increase. We will call this 'Type L agglomeration economies'. Therefore, whereas in the former case, the agglomeration economies affect the efficiency of using both inputs in equal proportions, in the latter situation only the efficiency of the labour input is directly scale dependent (to be precise, exclusively on the scale of the labour force).

It is not clear which of these two types of agglomeration externalities would be more relevant in reality. Both formulations have been used in the literature. Sullivan (1986), for instance, uses Type Q agglomeration effects, whereas Arnott (1979) and Fujita (1989, Section 8.2) use Type L. De Groot (2000) discusses both in the context of endogenous growth - in a non-spatial setting - and dubs Type Q 'learning by doing' and Type L 'learning by watching'. There is, in fact, a story to tell for both types. Type Q externalities, for instance, might reflect the situation where with a growing aggregate production, some firms may specialize in intermediate goods, which would increase the efficiency of urban production. Type L 
externalities may be relevant when a larger workforce enables a further specialization of labour, probably suiting personal capabilities more closely, or a larger probability of innovations when more hours are being spent working. Because of the different implications in the context of the present paper, we will consider both types. It can be emphasized that, for a monocentric city with a competitive industry and negligible freight transport costs to be stable, some form of agglomeration externalities is required anyway, to prevent the collapse of the city due to firms moving to the fringe (see also Fujita, 1989). ${ }^{2}$

In the numerical model, we will use the following function form to make A a function of either Q or L:

$$
\begin{aligned}
& A=1+\alpha_{Q} \cdot Q^{a g g l_{Q}} \\
& A=1+\alpha_{L} \cdot Q^{a g g l_{L}}
\end{aligned}
$$

Therefore, we use a simple exponential relation, where $a g g l_{Q}$ or $a g g l_{L}$ are very likely to be (and will restricted to be) smaller than one. The fixed unitary factor can be interpreted as the efficiency parameter for a firm that would choose to locate outside the CID. Again, agglomeration externalities are assumed to be strictly localized. A formulation where agglomeration externalities would follow a distance decay relation; that is, would depend on the proximity-weighted mass of production and labour at a location, would be an interesting extension in the situation where the CID were not modelled as a spaceless point.

As stated just before sub-section 2.2.1, the price of energy $\mathrm{p}_{\mathrm{E}}$, and the price of the final product $\mathrm{p}$ can be treated as given. In equilibrium, we know that a cost minimizing combination of $\mathrm{L}$ and En will be used, which implies (assuming that no taxes or subsidies are employed; see also (21') below):

$$
E n=L \cdot \frac{p_{E}^{r-1} \cdot \delta_{E}^{-r}}{w^{r-1} \cdot \delta_{L}^{-r}}
$$

(see the Appendix). Equation (21) shows that (and how) less energy will be used, relative to labour, if the price of energy, relative to the wage rate, increases (note that $r \leq 1$ by definition). Consistent with our assumption of perfect competition, we assume that no profits are made. Again under absence of any taxes or subsidies (see also (22') below), this implies, given that the product price should be equal to average production costs:

$$
p=\frac{1}{A} \cdot\left(\left(\frac{w}{\delta_{L}}\right)^{r}+\left(\frac{p_{E}}{\delta_{E}}\right)^{r}\right)^{\frac{1}{r}}
$$

(see the Appendix). Finally, we specify the following pollution function, which sets the emissions E proportional to the use of energy:

$E=\varepsilon \cdot E n$

\footnotetext{
${ }^{2}$ A specific type of agglomeration economies that has recently received attention, but that we cannot study explicitly in our single-sector setting, concerns the increase in the number of product variants on offer (Fujita $e t$ al., 1999). In particular when also environmental externalities would vary across sectors, this might offer a worthwhile future extension of the present analysis.
} 


\subsection{General spatial equilibrium}

The general spatial equilibrium model described in the preceding sub-sections has 17 unkowns, some of which are a function of $\mathrm{z}$. These unknowns are $\mathrm{w}, \mathrm{m}(\mathrm{z}), \mathrm{r}(\mathrm{z}), \mathrm{R}, \mathrm{K}, \mathrm{y}(\mathrm{z}), \mathrm{Y}, \mathrm{s}(\mathrm{z}), \mathrm{n}(\mathrm{z})$, $\mathrm{T}_{\mathrm{f}}(\mathrm{z}), \mathrm{L}, \mathrm{z}^{*}, \mathrm{En}, \mathrm{E}, \mathrm{Eq}(\mathrm{z}), \mathrm{Q}$ and $\mathrm{A}$ (recall that $\mathrm{p}_{\mathrm{E}}, \mathrm{r}_{\mathrm{A}}, \mathrm{p}$ and $\mathrm{N}$ are given; the other magnitudes are clearly parameters). The 17 equations needed to solve this system are (2), (3), (5a-c), (11)(16) and (18)-(23) with of course either one of (20a) and (20b). For other types of utility and production functions, as long as they imply unique conditional (factor) demands, a similar equality of numbers of equations and unkowns should in principle hold.

In our list of equations, we did not include the 'aggregate demand equals aggregate supply' relation, which in our partly open system reads:

$p \cdot(Q-Y)=r_{A} \cdot z^{*}+p_{E} \cdot E n$

Equation (24) states that the value of the city's production in excess of its local consumption should be just sufficient to pay for the purchase of land against the exogenous terms of trade $r_{A} / p$ plus energy against the exogenous terms of trade $p_{E} / p$. The share of local production not exported is consumed locally. The reason for not including this equilibrium condition explicitly is that it will be automatically satisfied under the zero profit condition. To see why, first observe that zero profits imply that:

$p \cdot Q=p_{E} \cdot E n+w \cdot L$

Because all rents exceeding $r_{A}$ are redistributed among the population, the total wage sum $w \cdot L$ is spent on the consumption of the industrial product and on the consumption of land against the agricultural price $\mathrm{r}_{\mathrm{A}}$ :

$w \cdot L=p \cdot Y+r_{A} \cdot z^{*}$

Substitution of (26) into (25) immediately yields (24).

It is if course not possible to obtain any further analytical (equilibrium) results for the model presented thus far. We therefore now move to the results of a numerical illustration, in order to study the comparative static properties of the free-market and some second-best and first-best equilibria.

\section{A numerical example}

\subsection{The base-case under non-intervention}

The numerical model is fully consistent with the analytical model just presented. Three more variables are introduced, which are a possible tax on energy, $\tau_{\mathrm{E}}$, which the local government might use for internalizing the environmental externality, and possible subsidies on production and labour, $\sigma_{\mathrm{Q}}$ and $\sigma_{\mathrm{L}}$, which the local government might use for internalizing the agglomeration externality. Clearly, the $\sigma$ 's could have been defined as a tax, but since we expect negative first-best and second-best taxes for an external benefit, the current representation seems somewhat more intuitive.

In our general equilibrium framework, the addition of taxes and subsidies leads to a number of changes in the equations presented above. First, equation (3) should reflect that any net tax revenue surpluses or deficits will not be accumulated, but will be redistributed among 
(financed by) the population. It is assumed that this is done in a lump-sum, uniform fashion. The local taxes and subsidies leave the three exogenous prices $\mathrm{p}, \mathrm{r}_{\mathrm{A}}$ and $\mathrm{p}_{\mathrm{E}}$ unaffected. For the two 'terms of trades' $r_{\mathrm{A}} / \mathrm{p}$ and $\mathrm{p}_{\mathrm{E}} / \mathrm{p}$ this reflects a 'small city assumption', for $\mathrm{p}$ this reflects that local producers cannot charge a different price to local consumers than they charge for their exports, which is consistent with the assumption that freight transport costs are negligible. A subsidy on labour means that producers effectively pay a wage equal to $\mathrm{w}-\sigma_{\mathrm{L}}$, when workers receive $\mathrm{w}$. This all means that we have to revise the following equations:

$$
\begin{aligned}
& M(z)=\frac{R+\tau_{E} \cdot E n-\sigma_{Q} \cdot Q-\sigma_{L} \cdot L}{N}+w \cdot(T-t \cdot z) \\
& E n=L \cdot \frac{\left(p_{E}+\tau_{E}\right)^{r-1} \cdot \delta_{E}^{-r}}{\left(w-\sigma_{L}\right)^{r-1} \cdot \delta_{L}^{-r}} \\
& p+\sigma_{Q}=\frac{1}{A} \cdot\left(\left(\frac{w-\sigma_{Q}}{\delta_{L}}\right)^{r}+\left(\frac{P_{E}+\tau_{E}}{\delta_{E}}\right)^{r}\right)^{\frac{1}{r}}
\end{aligned}
$$

Note that $(5 \mathrm{a}-\mathrm{c})$ remain unaffected, since the prices used in the preceding section now still

\begin{tabular}{|c|c|c|c|}
\hline \multicolumn{2}{|c|}{ Parameters } & \multicolumn{2}{|c|}{ Base-case equilibrium values of some key variables } \\
\hline $\begin{array}{l}\alpha_{\mathrm{Q}}=2 \\
\mathrm{aggl}_{\mathrm{Q}}=0.075 \\
\alpha_{\mathrm{s}}=0.15 \\
\alpha_{\mathrm{y}}=0.35 \\
\alpha_{\mathrm{f}}=0.5 \\
\alpha_{\mathrm{e}}=0.5 \\
\mathrm{a}=0.25 \\
\delta_{\mathrm{L}}=5 \\
\delta_{\mathrm{E}}=15 \\
\rho=-0.35 \Rightarrow \mathrm{r}=0.26 ; \sigma=0.74 \\
\varepsilon=1.5 \cdot 10^{-5}\end{array}$ & $\begin{array}{l}\mathrm{N}=1000 \\
\mathrm{~T}=16 \\
\mathrm{t}=0.1 \\
\mathrm{p}=25 \\
\mathrm{p}_{\mathrm{E}}=35 \\
\mathrm{r}_{\mathrm{A}}=17500 \\
\\
\text { Taxes and subsidies: } \\
\tau_{\mathrm{E}}=0 \\
\sigma_{\mathrm{Q}}=0 \\
\sigma_{\mathrm{L}}=0\end{array}$ & $\begin{array}{l}=29409 \\
Q=61549 \\
A=5.57 \\
L=7443 \\
E n=15228 \\
E=0.228 \\
\left(p+\sigma_{Q}\right) \cdot Q=1.54 \cdot 10^{6} \\
\left(w-\sigma_{L}\right) \cdot L=1.01 \cdot 10^{6} \\
\left(p_{E}+\tau_{E}\right) \cdot E n=0.53 \cdot 10^{6}\end{array}$ & $\begin{array}{l}\mathrm{p} \cdot(\mathrm{Q}-\mathrm{Y})=0.80 \cdot 10^{6} \\
\mathrm{p}_{\mathrm{E}} \cdot \mathrm{En}=0.53 \cdot 10^{6} \\
\mathrm{r}_{\mathrm{A}} \cdot \mathrm{z}^{*}=0.27 \cdot 10^{6} \\
\mathrm{z}^{*}=15.46 \\
\mathrm{R}=44547 \\
\mathrm{w}=135\end{array}$ \\
\hline
\end{tabular}
have the interpretation of consumers' prices. Because the exogenous prices have not changed, also (24) is still valid in its original form.

Table 1. Parameters and equilibrium values of some key variables in the base-case scenario

The left two columns of Table 1 show the parameter values we assumed for the base-case of our simulation model. The city has 1000 inhabitants, with a time endowment of 16 (hours per day). Some $49 \%$ of the time available after commuting will be spent working, and $30 \%$ $(100 \cdot 0.15 /(0.15+0.35))$ of the monetary budget will be allocated to rent, the remaining share being used for the consumption of the industrial good. The substitution elasticity in the production function is 0.74 . With the other parameters chosen as they are, some $53 \%$ of all production costs involve the polluting input, energy. Around $50 \%$ of the local production is exported to finance the energy input and the rent of urban land at the agricultural price $\mathrm{r}_{\mathrm{A}}$. The city's size is 15.5 (kilometers), implying that total commuting time at the city edge is 1.5 (hours) for a round-trip: nearly $10 \%$ of the total available time. As a consequence, time 
worked and leisure time fall from 7.8 and 8.2 at $\mathrm{z}=0$ to some 7.1 and 7.4 at $\mathrm{z}=\mathrm{z}^{*}$, respectively. It can be checked easily in the right two columns that the equilibrium conditions (24) and (25), and hence (26), are fulfilled: there are zero profits and there is a 'trade balance'. The environmental quality in the CID is some $77 \%$ of the virgin state, and is over $99 \%$ at $\mathrm{z}=\mathrm{z}^{*}$. Because $\alpha_{e}$ is set at 0.5 , this means that someone living in the CID would be indifferent between obtaining a virgin state environmental quality or a $13 \%$ increase in the availability of all other goods in the utility function, keeping everything else constant. These figures should give some adequate overall impression of the assumed base-case.

(a)
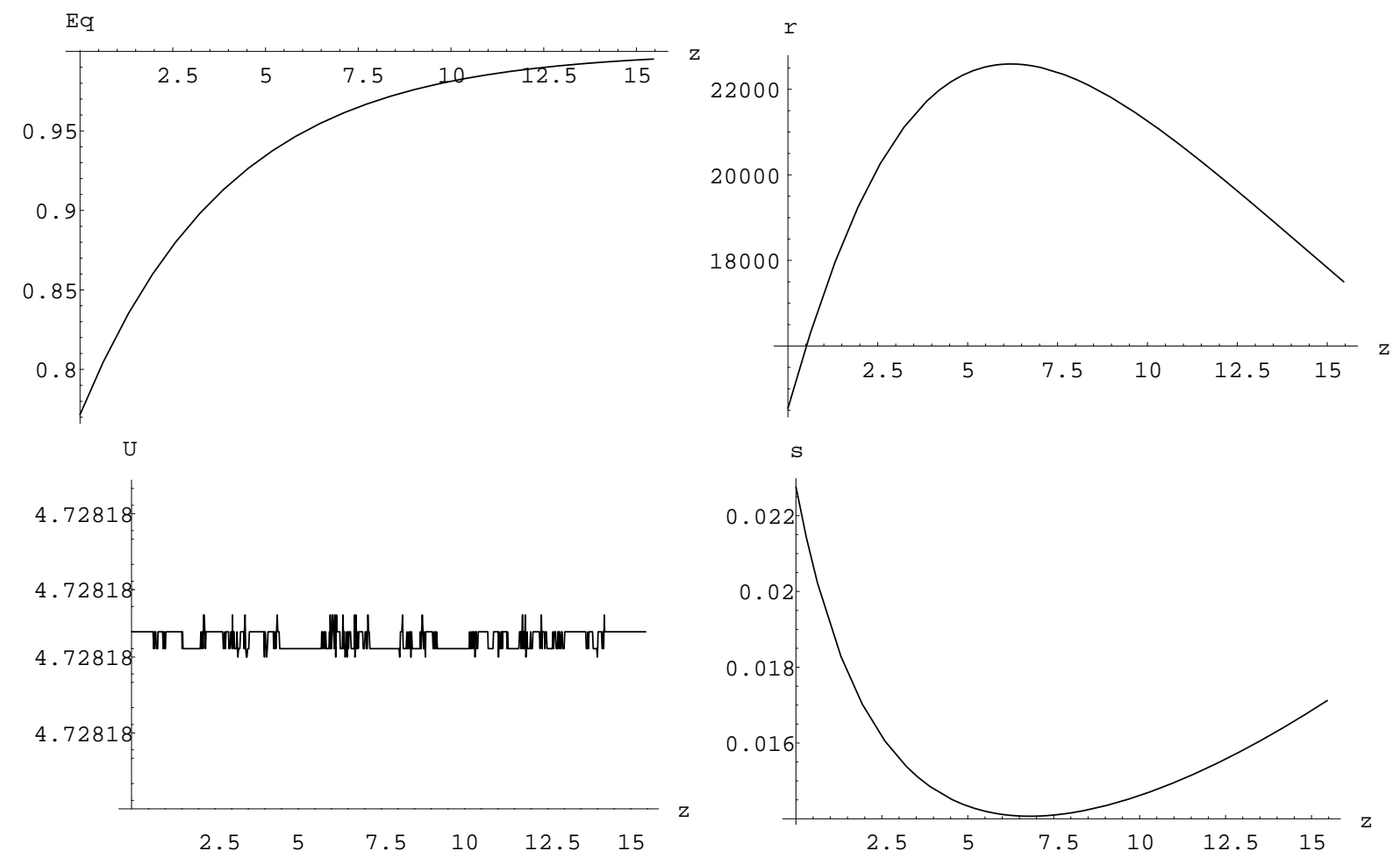

(d)

Figure 1: Environmental quality (a), land rents (b), lot size (c) and utility $(d)$ as a function of distance in the base-case equilibrium

Apart from the mentioned 'non-spatial' figures, it is of course interesting to see how some of the variables vary over space in the base-case equilibrium. Figure 1a-d depicts the patterns of $\mathrm{Eq}(\mathrm{z}), \mathrm{r}(\mathrm{z}), \mathrm{s}(\mathrm{z})$, and $\mathrm{U}(\mathrm{z})$, respectively. Figure 1a shows how the environmental quality follows an exponential distance-decay pattern. As a result, this model does not yield the familiar pattern where land rents fall monotonously with an increasing distance from the city centre. Instead, consistent with a partial equilibrium prediction from O'Sullivan (1996), r(z) follows an inverted U-shape, where a maximum is reached at a value of $\mathrm{z}$ of around 7. As stated when discussing equation (11), the equilibrium value of land-rent in the residential area will be the outcome of a "tug-of-war" between the effects of environmental quality on the one hand, and commuting costs on the other. Closer to the city centre, the rapidly worsening 
environmental quality starts dominating this tug-of-war. However, when moving outwards, $\mathrm{Eq}(\mathrm{z})$ becomes flatter, and the (linear) impact of commuting costs starts dominating. At the CID, the environmental quality is affected so much, that the land-rent has even fallen below the agricultural rent. ${ }^{3}$ Consistent with the pattern of land-rent, people will choose the relatively smallest lot sizes at an intermediate distance from the CID. In the base-case, the smallest lot size of around 0.014 (14 meters) is found at $\mathrm{z}$ of around 7.

Finally, the inclusion of Figure 1d serves to illustrate that indeed a spatial equilibrium in the residential area is obtained: utility is constant over place. The fluctuation shown, evidently, is due only to numerical imprecision in the simulation model.

Having discussed the most important features of the base-case equilibrium, we now move to a discussion of the qualitative properties of the equilibria as they arise under various forms of regulation. We first discuss the impact of energy taxes under the assumption that agglomeration externalities do not exist; i.e., under a given value of $\mathrm{A}$. This has an advantage in exposition, as it helps us illustrate the impact of regulating the environmental externality without there being a feedback on production efficiency. We then move on to the use of energy taxes alone, and energy taxes in combination with production subsidies in case Type Q agglomeration economies exist; and then consider the use of energy taxes alone, and energy taxes in combination with labour subsidies with Type L agglomeration economies.

\subsection{Environmental regulation in absence of agglomeration externalities}

In absence of agglomeration externalities, there is still one externality left in the model, namely the environmental externality. As a result, the free-market configuration will not be efficient, and an environmental tax can be expected to lead to a Pareto-improvement. ${ }^{4}$ From a modelling perspective, the agglomeration externalities can simply be 'switched off' by setting A constant and equal to its base-case value of 5.57. ${ }^{5}$ Table 2 shows some important features of the firstbest optimum of the resulting model, relative to the free-market configuration described in Section 3.1.

The optimal environmental tax on energy amounts to $4.35^{6}$, implying a $12.4 \%$ increase in the energy price, and making up 3.95\% of the firm's average production costs of 25 in the optimum. As a result, production will decline with $7.33 \%$, energy use with $15.03 \%$, and labour input with $3.17 \%$. As one could expect, therefore, the use of the energy tax leads both to a

\footnotetext{
${ }^{3}$ Indeed, it is implicitly assumed that no farmer would move into the city and out-bid residential land-use by offering a land-rent $r_{A}$. This could be justified if the reduced environmental quality would reduce the agricultural productivity of land, too. Outside the city, the constancy of $r_{\mathrm{A}}$ would then be an approximation, only.

${ }^{4}$ When also the environmental externality is eliminated by setting $\varepsilon=0$, so that no externalities remain, the freemarket spatial economic equilibrium in the (simulation) model coincides with the Pareto efficient configuration, which is consistent with what can be expected on the basis of standard urban economic theory (e.g. Fujita, 1989).

${ }^{5}$ Of course, implicitly, it then has to be assumed that outside the CID, A obtains a lower value, because otherwise the monocentric city would not be stable. In particular, producers would have an incentive to locate at the city fringe, where labour is cheaper in the sense that the benefit of saved commuting time can be mutually exploited by the producers and workers.

${ }^{6}$ All first-best and second-best optimal taxes reported in this paper were found by numerical optimization.
} 
reduction in overall production, and to a relative switch from the energy input towards the labour input. The endogenous wage rate has decreased by some $6 \%$. A full explanation for this result of course requires a complete tracing of all equilibrating processes in the model, but the decrease in any case reflects that in the optimum, the marginal productivity of labour has decreased due to the reduced energy input, and hence so has the producers' marginal willingness to pay for labour. At the same time, the consumption of leisure time has increased, which reduces the marginal utility of leisure and hence the required wage rate to supply a marginal unit of labour. The said increase in the consumption of leisure, in turn, is due to a shift from the consumption of the polluting industrial good towards the consumption of leisure, and to the average increase in the time budget after commuting $(\mathrm{T}-\mathrm{t} \cdot \mathrm{z})$ that results from the reduction in city size (see below).

\begin{tabular}{|l|l|}
\hline \multicolumn{1}{|c|}{$\begin{array}{c}\text { Prices } \\
\text { (base case values between brackets, when different } \\
\text { from current values) }\end{array}$} & \multicolumn{1}{c|}{$\begin{array}{c}\text { Relative changes of the equilibrium values of some } \\
\text { key variables } \\
\text { (percentage change) }\end{array}$} \\
\hline $\mathrm{p}=25$ & $\mathrm{Q}: 92.67 \%$ \\
$\mathrm{p}_{\mathrm{E}}=35$ & En: $84.97 \%$ \\
$\mathrm{w}=126.80(135.12)$ & $\mathrm{L}: 97.14 \%$ \\
& Y: $96.83 \%$ \\
$\sigma_{\mathrm{Q}}=0$ & $\mathrm{z}: 96.53 \%$ \\
$\tau_{\mathrm{E}}=4.35(0)$ & \\
$\sigma_{\mathrm{L}}=0$ & \\
& \\
$\mathrm{p}+\sigma_{\mathrm{Q}}=25$ & \\
$\mathrm{p}_{\mathrm{E}}+\tau_{\mathrm{E}}=39.35(35)$ & \\
$\mathrm{w}-\sigma_{\mathrm{L}}=126.80(135.12)$ & \\
\hline
\end{tabular}

Table 2. First-best optimum in absence of agglomeration externalities

Figure 2 depicts the spatial implications of optimal energy taxation. Figure 2a shows that the environmental quality has improved throughout the city, the largest absolute improvements of course occurring near the CID. As a result, central residential locations become relatively more attractive, and the equilibrium land rent increases near the CID and decreases at more remote locations (Figure 2b). The decrease in the consumption of space near the CID (Figure 2c) should therefore not come as a surprise, but the fact that also near the city fringe $\mathrm{s}(\mathrm{z})$ has decreased may seem puzzling. Again, a full explanation of this phenomenon would require a full tracing of equilibrium effects through the entire model. Equation (5b), showing the equilibrium demand for space, is helpful. Apparently, the reduced wage rate in combination with the reduction of hours worked imply that the effect in the numerator of $(5 b)$ dominates the effect in the denominator. The improved environmental quality near the CID thus induces a move towards the CID, making the city more compact (3.47\% smaller than in the base case).

The conclusion is that, in absence of agglomeration externalities, the optimization of the environmental externality leads to a new spatial equilibrium, with a cleaner, smaller city in which people consume less of the polluting industrial good and more leisure (see also Figure $2 \mathrm{~d}$ ), and enjoy a higher utility level - which is tautological for a move to the optimum. 
A final remark is in order. It is important to emphasize that, although the external environmental effect is spatially differentiated, all citizens benefit to exactly the same extent from the optimization of the externality, despite the possible suggestion made by Figure $2 \mathrm{a}$. The reason is that in the optimal general spatial equilibrium, utility is again constant over space. In other words, simultaneous changes in land rents and relocation of victims of an environmental externality will lead to a situation in which the benefits of environmental policies exceed the area most heavily affected by pollution. Therefore, when an environmental externality is 'localized' from the physical viewpoint, it need not be localized from the economic viewpoint when - especially in the longer run - location and land rents are endogenous. Note that this latter conclusion would be valid also when lot sizes would be assumed fixed, which they normally would be in the medium run. Also in that case, sufficient mobility and freely adjusting land prices would lead to an equalization of utility over space.

(a)
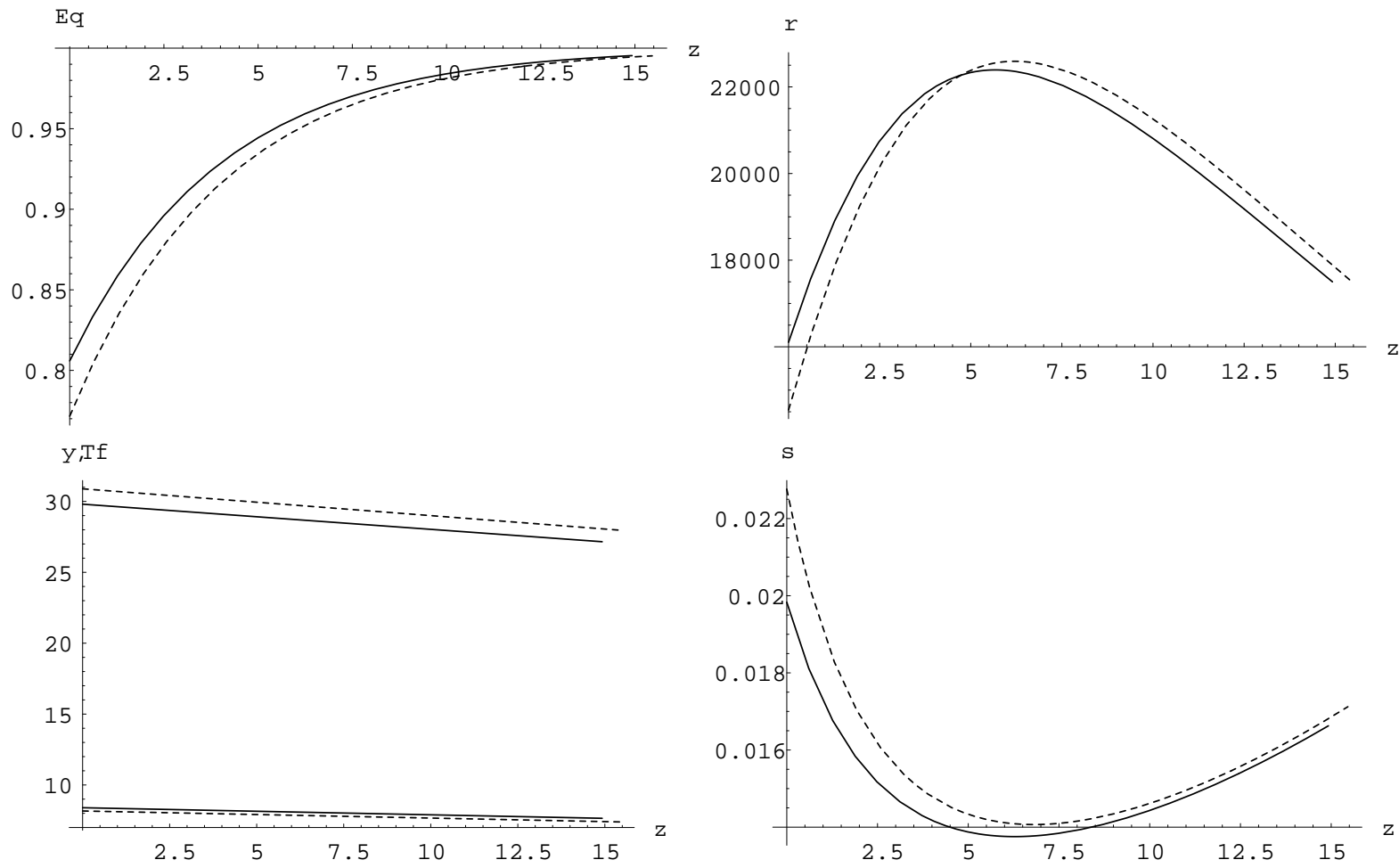

(d)

Note: the upper pair of curves in panel (d) represent $y$, the lower pair $T_{f}$

Figure 2: Environmental quality (a), land rents (b), lot size (c) and consumption of leisure and the industrial good (d) as a function of distance in the base-case equilibrium (dashed lines) and the firstbest optimum in absence of agglomeration externalities (solid lines)

At the same time, defensive behaviour by victims - in the present situation reflected by a relatively low population density near the CID - leads to a situation where in the free market equilibrium, the marginal external environmental costs are lower than what they would have been with the same emissions and a population density function fixed at its optimal pattern 
consistent with Figure 2c. Equivalently, the introduction of environmental taxes, attracting people to locations closer to the CID leads to an upward shift of the marginal external costs as a function of the emission level alone. The first-best optimal tax will thus be higher than the level that would be predicted keeping locations fixed. Such defensive behaviour by victims is in principle efficient (Oates, 1983; Verhoef, 1994), in the sense that no taxes or subsidies affecting locations are called for to secure an optimal location pattern as long as the environmental externality is optimized. It does mean, however, that in the non-intervention equilibrium, the inefficiencies due to excessive pollution not only entail the direct effect of a reduced environmental quality, but also more hidden, indirect effects that result from excessive defensive behaviour. In the present setting, this includes all effects that result from the tendency to choose a more remote location, in particular increased travel times and decreased labour supply and consumption of leisure.

\subsection{Second-best and first-best taxation with Type $Q$ agglomeration externalities}

When Type Q agglomeration externalities exist, and explain the stability of the existing urban equilibrium, environmental taxation becomes relatively less attractive, as the reduction of emissions and production comes at the extra price of reduced agglomeration externalities. Indeed, in the model with A again calculated according to (20a), instead of kept fixed, the optimal level of the energy tax amounts to 1.20 (a $3.43 \%$ increase in energy price, implying a $1.16 \%$ share in the average production costs of 25), which is below the level of 4.35 found above for a constant value of A. This relatively low optimal tax level can be explained by the fact that in the current situation, a tax $\tau_{\mathrm{E}}$ on energy in fact has become a second-best tax: one single tax is available to affect two externalities. Whereas the first policy goal of optimizing the environmental externality would call for a relatively high value of $\tau_{\mathrm{E}}$, the other goal of optimizing the agglomeration externality would require the opposite.

\begin{tabular}{|c|c|c|c|}
\hline \multicolumn{2}{|c|}{$\begin{array}{c}\text { Prices } \\
\text { (base case values between brackets, when different } \\
\text { from current values) }\end{array}$} & \multicolumn{2}{|c|}{$\begin{array}{c}\text { Relative changes of the equilibrium values of some } \\
\text { key variables } \\
\text { (percentage change) }\end{array}$} \\
\hline Second-best: $\tau_{E}$ & First-best: $\tau_{E}$ and $\sigma_{Q}$ & Second-best: $\tau_{E}$ & First-best: $\tau_{E}$ and $\sigma_{Q}$ \\
\hline $\mathrm{p}=25$ & $\mathrm{p}=25$ & Q: $97.65 \%$ & Q: $99.28 \%$ \\
\hline $\mathrm{p}_{\mathrm{E}}=35$ & $\mathrm{p}_{\mathrm{E}}=35$ & En: $95.28 \%$ & En: $95.30 \%$ \\
\hline $\mathrm{w}=132.42(135.12)$ & $\mathrm{w}=139.58(135.12)$ & L: $99.16 \%$ & L: $101.55 \%$ \\
\hline & $-162(0)$ & $\begin{array}{l}\text { Y: } 98.92 \% \\
* .98 .86 \%\end{array}$ & Y: $101.81 \%$ \\
\hline $\begin{array}{l}\sigma_{\mathrm{Q}}=0 \\
\tau_{\mathrm{E}}=1.20(0)\end{array}$ & $\begin{array}{l}\sigma_{\mathrm{Q}}=1.62(0) \\
\tau_{\mathrm{E}}=4.39(0)\end{array}$ & & \\
\hline$\sigma_{\mathrm{L}}=0$ & $\sigma_{\mathrm{L}}=0$ & & \\
\hline $\mathrm{p}+\sigma_{\mathrm{Q}}=25$ & $\mathrm{p}+\sigma_{\mathrm{Q}}=26.62$ & & \\
\hline $\mathrm{p}_{\mathrm{E}}+\tau_{\mathrm{E}}=36.20$ & $\mathrm{p}_{\mathrm{E}}+\tau_{\mathrm{E}}=39.39$ & & \\
\hline $\mathrm{W}-\sigma_{\mathrm{L}}=132.42(135.12)$ & $\mathrm{w}-\sigma_{\mathrm{L}}=139.58(135.12)$ & & \\
\hline
\end{tabular}

Table 3. Second-best and first-best optimum with Type $Q$ agglomeration externalities 
The first and third column in Table 3 show the effects of using this second-best tax. Although smaller in size, the qualitative impacts are comparable to those found in the previous section. The same holds for the spatially differentiated impacts, depicted in Figure 4. To avoid repetition, a further interpretation of results will therefore not be given.

The existence of Type Q agglomeration externalities therefore makes energy taxation a relatively ineffective policy, as a second-best optimal use requires the trading-off of two opposing goals. A logical next question is whether this picture would change if a separate subsidy $\sigma_{\mathrm{Q}}$ is used, so that both externalities can be optimized separately. The second and fourth column in Table 3 show the main results of this, under the present circumstances, firstbest policy. Under such first-best regulation the optimal energy tax is considerably higher, and slightly exceeds the value in absence of agglomeration economics, with a value of 4.39 (a $12.54 \%$ increase in energy price, implying a $4.17 \%$ share in the consumers' price of 25 ). The optimal subsidy on production, internalizing the marginal agglomeration externality, amounts to 1.62 , which is $6.48 \%$ of the consumers' price of 25 .

(a)
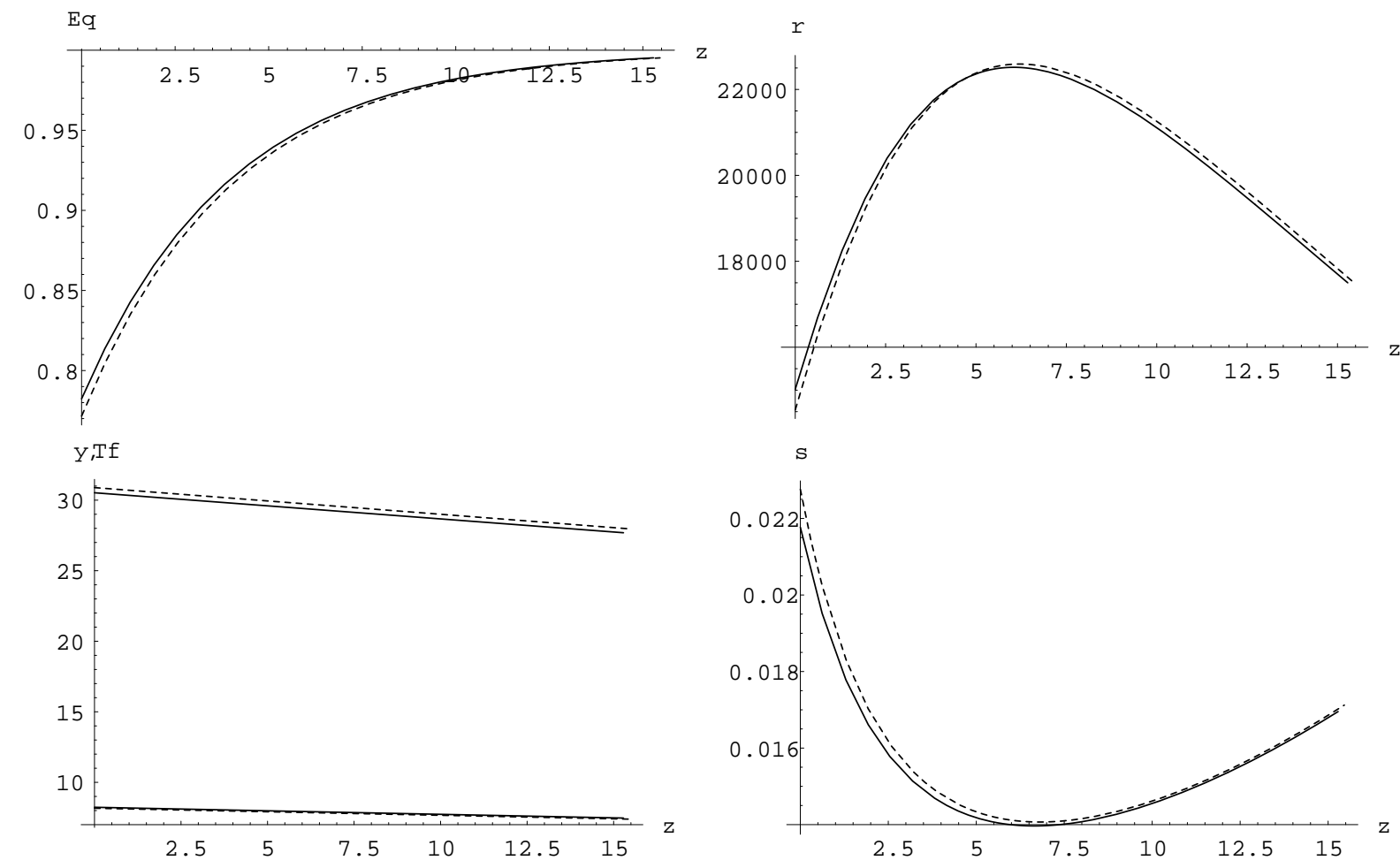

(d)

Note: the upper pair of curves in panel (d) represent $y$, the lower pair $T_{f}$

Figure 3: Environmental quality (a), land rents (b), lot size (c) and consumption of leisure and the industrial good (d) as a function of distance in the base-case equilibrium (dashed lines) and the second-best optimum with Type $Q$ agglomeration externalities and an energy tax alone (solid lines)

Interestingly, the first-best and second-best equilibrium hardly differ with respect to the equilibrium environmental quality. The positive effect of a higher production level on energy 
use in the first-best equilibrium is more or less off-set by the effect of stronger substitution towards the labour input, resulting from the higher energy tax. Figure $4 \mathrm{~d}$ shows that, with an internalization of the agglomeration externality, boosting production, throughout the city the consumption of leisure has decreased and that of the industrial good has increased - which is in contrast with the results presented earlier. These effects are consistent with the higher equilibrium wage rate and increased labour input in the first-best equilibrium (leading to a larger monetary budget), which in turn are consistent with the increased marginal value productivity of labour for the producers, given the subsidy on production. Figure $4 \mathrm{~b}$ shows that the higher budget induces the citizens to bid up land prices throughout the city, the strongest increases, however, still occurring near the CID where the environmental quality has improved most strongly. Despite the rent increase, the effect of a higher budget apparently dominates near the city fringe, where the consumption of space has increased. Overall, the size of the city has increased by some $0.25 \%$.

(a)
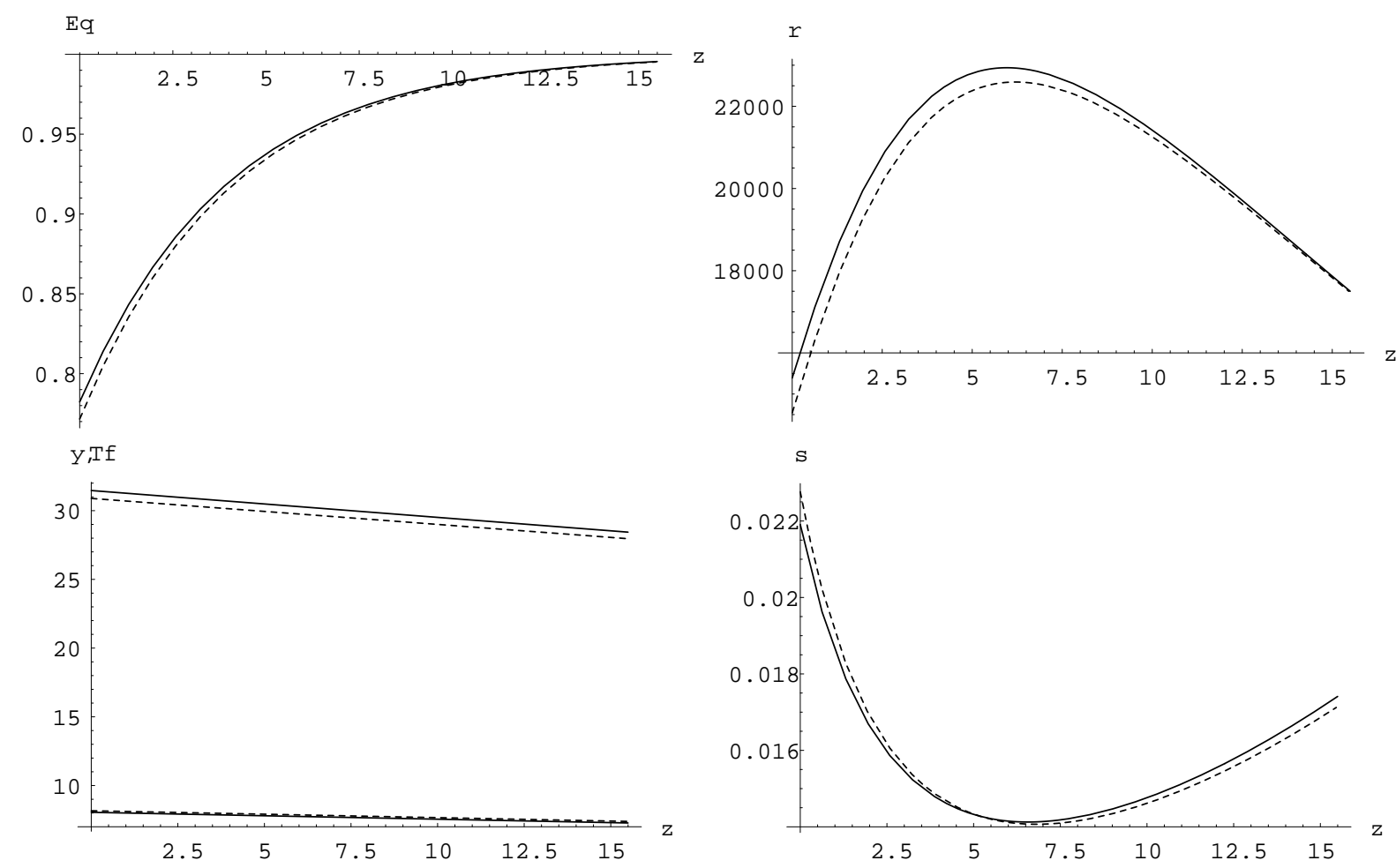

(d)

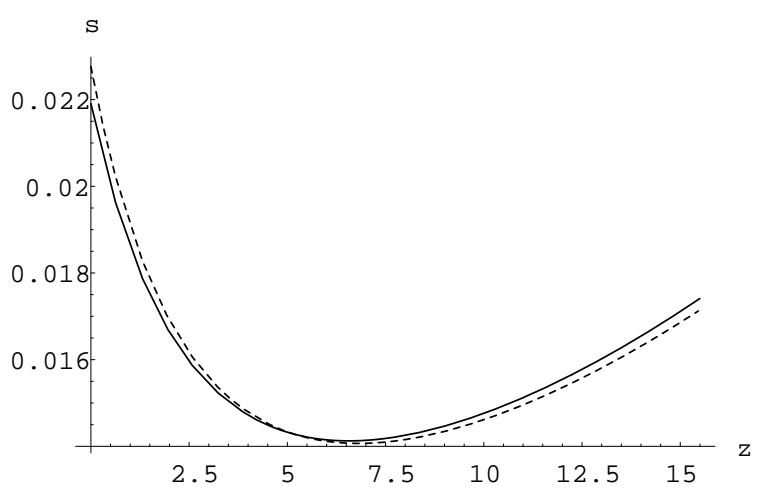

Note: the upper pair of curves in panel (d) represent $y$, the lower pair $T_{f}$

Figure 4: Environmental quality (a), land rents (b), lot size (c) and consumption of leisure and the industrial good (d) as a function of distance in the base-case equilibrium (dashed lines) and the firstbest optimum with Type $Q$ agglomeration externalities and an energy tax and a production subsidy (solid lines)

We conclude that in presence of Type Q agglomeration externalities, energy taxes used in isolation may lose at least some of their appeal as a means of improving overall efficiency. If 
the marginal agglomeration externality is large enough, it is not inconceivable that (positive) energy taxes alone may even become counterproductive, if the environmental benefit does not outweigh the indirect disadvantage due to the reduced efficiency resulting from a lower scale of urban production. At the same time, when used in optimal conjunction with subsidies encouraging urban production, energy taxes would be important for the purpose of simultaneously optimally exploiting the agglomeration externality while improving the environmental quality in the city, as the numerical example has shown.

\section{4. $\quad$ Second-best and first-best taxation with Type L agglomeration externalities}

If agglomeration economies depend on the scale of the labour force rather than on the scale of production, the two policy goals - limiting pollution at the one hand, exploiting external scale economies on the other - become less opposing. In particular, a tax on energy, apart from leading to a reduction in overall production, will induce a relative shift from energy to labour. Regardless of which of these two effects will dominate in the determination of the new equilibrium level of employment, i.e., regardless of whether there will be a net increase or decrease in employment, it can be expected that the negative effect of environmental taxation upon scale economies will be less severe with Type L than with Type Q agglomeration effects. In our model, we can investigate this by replacing (20a) by (20b). In terms of parameterization, the same non-intervention equilibrium was reproduced by setting $\operatorname{aggl}_{L}=\operatorname{aggl}_{Q}=0.075$ and $\alpha_{L}=2.343$.

\begin{tabular}{|c|c|c|c|}
\hline \multicolumn{2}{|c|}{$\begin{array}{c}\text { Prices } \\
\text { (base case values between brackets, when different } \\
\text { from current values) }\end{array}$} & \multicolumn{2}{|c|}{$\begin{array}{c}\text { Relative changes of the equilibrium values of some } \\
\text { key variables } \\
\text { (percentage change) }\end{array}$} \\
\hline Second-best: $\tau_{E}$ & First-best: $\tau_{E}$ and $\sigma_{L}$ & Second-best: $\tau_{E}$ & First-best: $\tau_{E}$ and $\sigma_{L}$ \\
\hline $\mathrm{p}=25$ & $\mathrm{p}=25$ & Q: $94.31 \%$ & Q: $96.65 \%$ \\
\hline $\mathrm{p}_{\mathrm{E}}=35$ & $\mathrm{p}_{\mathrm{E}}=35$ & En: $88.42 \%$ & En: $88.38 \%$ \\
\hline $\mathrm{w}=128.63(135.12)$ & $\mathrm{w}=138.86(135.12)$ & L: $97.85 \%$ & L: $101.33 \%$ \\
\hline & & $\begin{array}{l}Y: 91.48 \% \\
* 0700\end{array}$ & $Y: 101.66 \%$ \\
\hline$\sigma_{\mathrm{Q}}=0$ & $\sigma_{\mathrm{Q}}=0$ & $\mathrm{Z}: 97.28 \%$ & z:99.31\% \\
\hline $\begin{array}{l}\tau_{\mathrm{E}}=3.20(0) \\
\sigma_{\mathrm{I}}=0\end{array}$ & $\tau_{\mathrm{E}}=4.48(0)$ & & \\
\hline$\sigma_{\mathrm{L}}=0$ & $\sigma_{\mathrm{L}}=12.13(0)$ & & \\
\hline $\mathrm{p}+\sigma_{\mathrm{Q}}=25$ & $\mathrm{p}+\sigma_{\mathrm{Q}}=25$ & & \\
\hline $\mathrm{p}_{\mathrm{E}}+\tau_{\mathrm{E}}=38.20$ & $\mathrm{p}_{\mathrm{E}}+\tau_{\mathrm{E}}=39.48$ & & \\
\hline $\mathrm{w}-\sigma_{\mathrm{L}}=128.63(135.12)$ & $\mathrm{w}-\sigma_{\mathrm{L}}=126.73(135.12)$ & & \\
\hline
\end{tabular}

Table 4. Second-best and first-best optimum with Type L agglomeration externalities

The first and third column in Table 4 show the effects of the second-best policy of using $\tau_{\mathrm{E}}$ alone in the present setting. Although still not as high as in absence of agglomeration externalities (Section 3.2), the second-best energy tax is considerably higher with Type L than with Type Q agglomeration externalities: 3.20 (a 9.14\% increase in energy price, implying a $2.97 \%$ share in the average production cost price of 25). This higher second-best optimal value reflects that the instrument is relatively more efficient than in case of Type Q externalities. 
Figure 5 shows that the spatial impacts are again qualitatively the same as those resulting from an energy tax in absence of agglomeration externalities; albeit again slightly smaller in size. A further discussion is therefore omitted. Note, however, that despite the beneficial side-effect of energy taxes encouraging the use of labour relative to energy, the production size effect dominates, and equilibrium labour demand and supply have declined by some $2.15 \%$. It is, however, not inconceivable that under a different parameterization, for instance with a larger substitution elasticity, the substitution effect would dominate and equilibrium labour demand and supply would increase, in which case a tax on energy would directly lead to a more efficient production as represented by an increase in $\mathrm{A}$.

The first-best policy in this case involves the joint use of an energy tax $\tau_{\mathrm{E}}$ and a subsidy on labour $\sigma_{\mathrm{L}}$, where the latter of course serves to internalize the agglomeration externality. The optimal energy tax $\tau_{\mathrm{E}}$ amounts to 4.48 (a $12.80 \%$ increase in energy price, implying a $4.05 \%$ share in the average production cost price of 25), and the optimal subsidy on labour $\sigma_{\mathrm{L}}$ is 12.13 ( $8.74 \%$ of the net wage in the optimum, implying a $6.15 \%$ share in the average production cost price of 25).

(a)
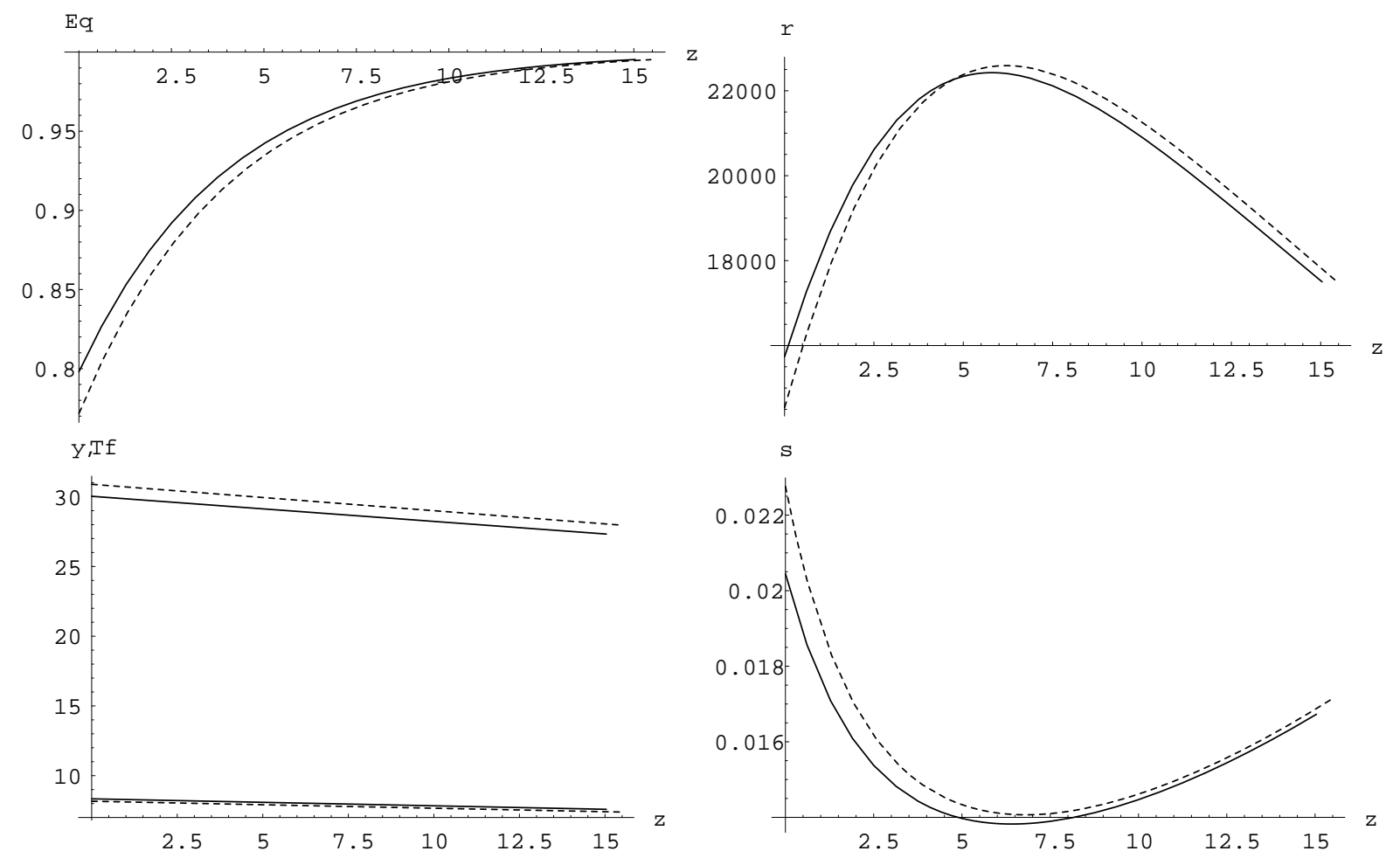

(d)

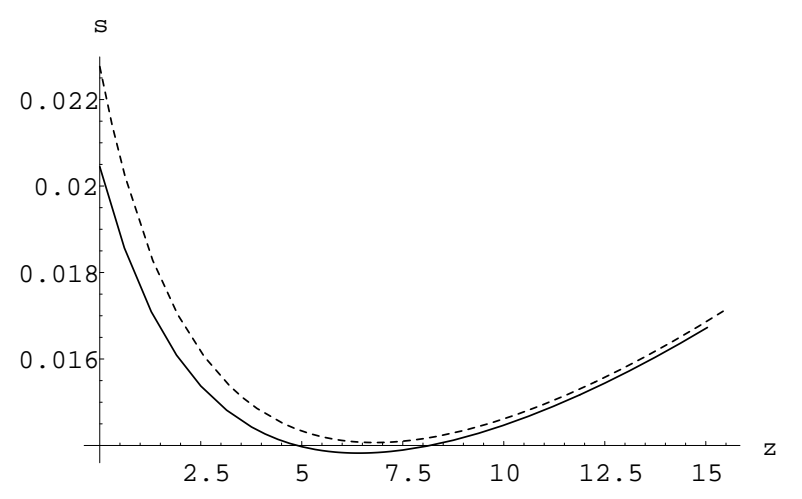

(c)

Note: the upper pair of curves in panel (d) represent $y$, the lower pair $T_{f}$

Figure 5: Environmental quality (a), land rents (b), lot size (c) and consumption of leisure and the industrial good (d) as a function of distance in the base-case equilibrium (dashed lines) and the second-best optimum with Type L agglomeration externalities and an energy tax alone (solid lines) 
As was the case with Type Q externalities, Figure 6a shows that the equilibrium environmental quality hardly differs between the second-best and first-best equilibrium (compare with Figure 5a). Furthermore, Figure $6 \mathrm{~d}$ shows that the higher wage have again induced people to consume less leisure and more of the industrial good. The explanation is the same: the effects are consistent with the higher equilibrium wage rate and increased labour input in the first-best equilibrium (leading to a larger monetary budget), which in turn are consistent with the increased marginal value productivity of labour for the producers, given the subsidy on labour. Also Figures $6 \mathrm{~b}$ and $6 \mathrm{c}$ show patterns similar to those in Figures $4 \mathrm{~b}$ and $4 \mathrm{c}$, albeit that in this case the city has reduced somewhat in size (by $0.69 \%$ ).

(a)
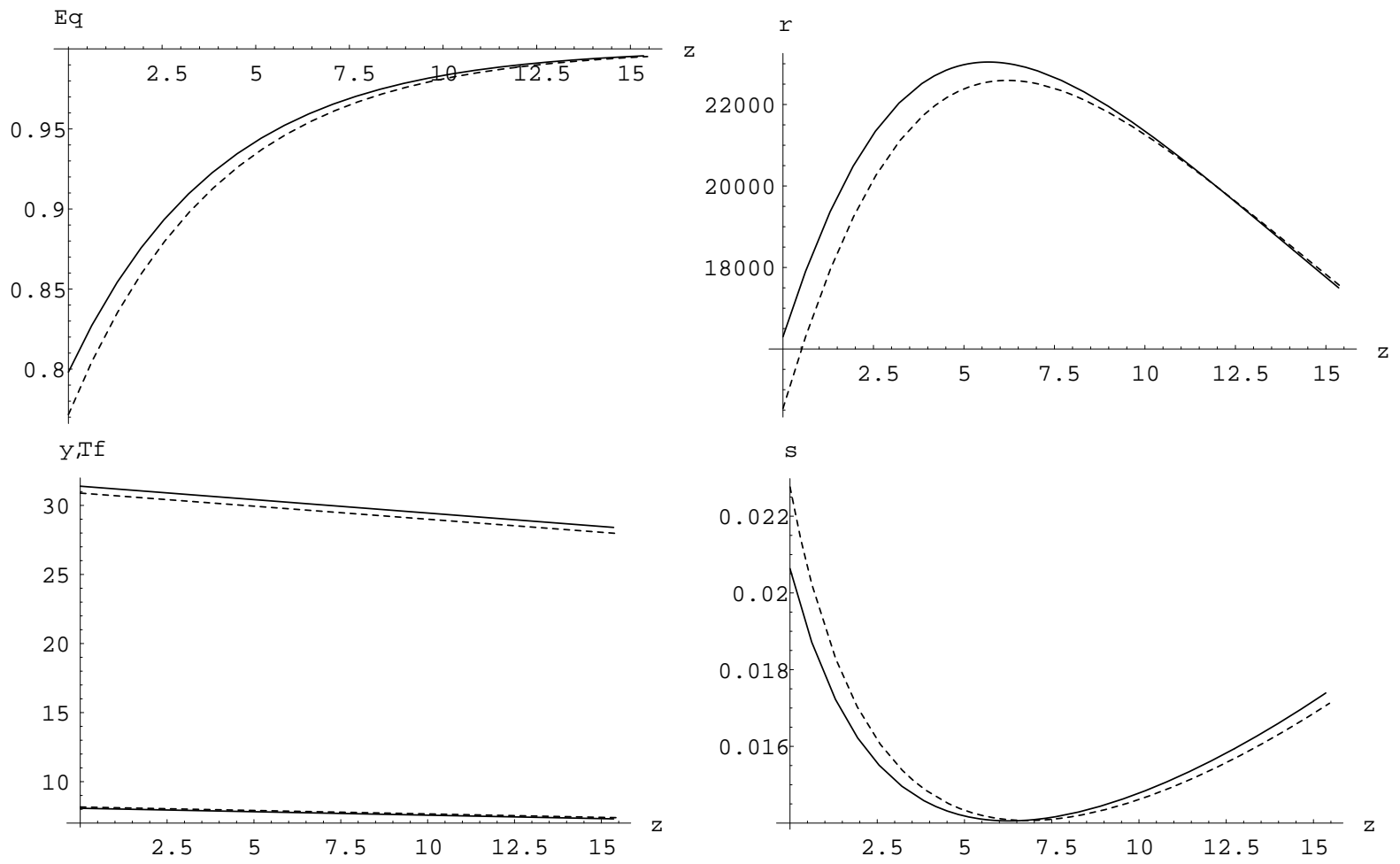

(d)

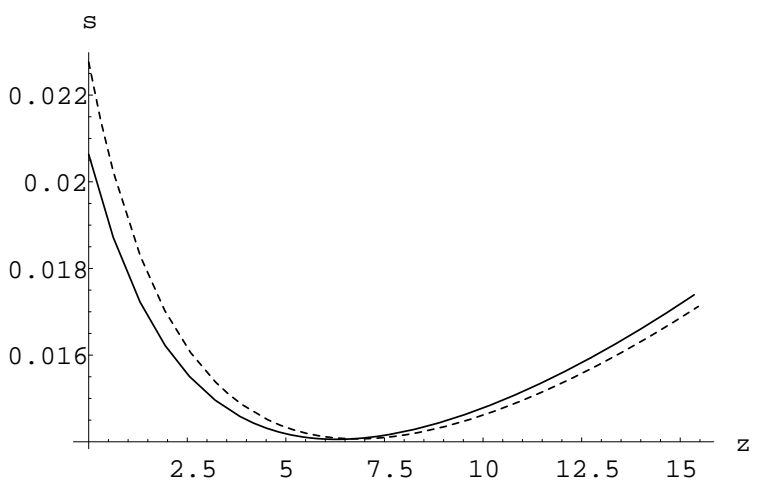

(c)

Note: the upper pair of curves in panel (d) represent $y$, the lower pair $T_{f}$

Figure 6: Environmental quality (a), land rents (b), lot size (c) and consumption of leisure and the industrial good $(d)$ as a function of distance in the base-case equilibrium (dashed lines) and the firstbest optimum with Type L agglomeration externalities and an energy tax and a labour subsidy (solid lines)

We conclude that with Type L agglomeration externalities, the two policy goals of environmental quality on the one hand and agglomeration efficiency on the other are still at odds with each other, in the sense that even in the optimum, the one goal would require a further increase in production and the other a decrease, although the incompatibility is likely to be smaller than with Type Q agglomeration externalities once substitution between energy and labour is allowed for. As a result, the use of energy taxes alone becomes more attractive 
relative to the case where Type Q externalities prevail, although first-best regulation of course still requires the use of two separate taxes, each specifically targeted to one policy goal.

\section{Conclusion}

In this paper, we used a general spatial equilibrium model to investigate the interactions between environmental externalities and agglomeration externalities in an urban context. This question has immediate policy relevance because of their likely simultaneous occurrence in most cities. Whereas urban production often leads to a deterioration of urban environmental quality, agglomeration externalities will generally be relevant too, and are even among the most important economic explanations for the sheer existence of cities. Our modelling framework for studying the interactions between these two types of externalities included complex mutual interactions between production, pollution, urban environmental quality, locational choices, endogenous labour supply, energy use and agglomeration externalities, while allowing for input substitution and considering full general equilibrium effects.

A number of general conclusions emerge from our analysis. Whereas the primary economists' reflex when confronted with environmental pollution would be to advice some form of internalization through taxation, our analysis has demonstrated that care should be taken with this instrument in an urban context. Although first-best environmental taxes are unambiguously positive, significantly lower values are found in second-best situations, in which agglomeration externalities are not optimally internalized. Second-best negative taxes are not inconceivable, in which case a naïve use of Pigouvian taxes - ignoring the negative side-effects on agglomeration externalities - would be welfare reducing. Despite the theoretical importance of agglomeration externalities for the existence of cities, the empirical measurement is difficult, and explicit policies directed towards the internalization of these externalities are not often observed (Anas et al., 1998). This implies that the second-best policies considered in this paper will be rule rather than exception in reality, implying that a naïve use of Pigouvian taxes - as if first-best conditions prevail throughout the urban economy - may indeed lead to unexpected negative side-effects. However, this risk is smaller if Type $\mathrm{L}$ rather than Type Q agglomeration externalities prevail. This implies that for a second-best (as well as hypothetical first-best) use of Pigouvian taxes, one not only has to take account of the existence of agglomeration externalities, but should also carefully assess the nature and (marginal) relevance of these effects.

It was demonstrated that environmental externalities that are localized from the physical perspective may not be so from the economic perspective. In particular, in the long run, mobility of households and adjusting land prices will lead to a process of equalization of utility over space. Defensive behaviour by victims - in our model reflected by a relatively low population density near the CID, and an inverted $U$ shaped rent gradient - leads to a situation where in the free market equilibrium, the marginal external environmental costs are lower than what they would have been with the same emissions and a population density function fixed at its optimal pattern. The first-best optimal tax will thus be higher than the level that would be predicted keeping locations fixed. Such defensive behaviour by victims is in principle efficient. 
It does mean, however, that in the non-intervention equilibrium, the inefficiencies due to excessive pollution not only entail the direct effect of a reduced environmental quality, but also more hidden, indirect effects that result from excessive defensive behaviour. In our model, this includes all effects that result from the tendency to choose a more remote location, in particular increased travel times and decreased labour supply and consumption of leisure. Comparable mechanisms are likely to apply also at a larger spatial scale, exceeding a single urban area. This creates challenges both for the measurement of (marginal) environmental costs, and for the design of (optimal) environmental policies in a spatial context. At the same time, it means that an additional type of interdependence may be relevant in the long run for situations where regions or countries engage in policy competition with respect to environmental quality and policies (e.g. Verhoef and Nijkamp, 1998).

The analysis has further demonstrated that even in a simple monocentric single-sector sector, the direct and indirect effects of environmental regulation are manifold. In the longer run, it will for instance affect locational behaviour, labour supply, and the size of cities, even with a constant population. This means that in reality, equilibrium first-best and second-best optimal tax levels will be even harder to predict than is suggested by the observation that marginal environmental costs and marginal agglomeration externalities are hard to express in single monetary values. Further complexities would of course arise when account is taken of in-migration into the city following from a higher utility level, the existence of multiple sectors, and heterogeneity of households. Moreover, apart from pollution and agglomeration effects, other externalities - traffic congestion, crowding, segregation - are likely to further complicate things in reality. All in all, one can safely predict a fertile research area for the study of urban externalities - both in isolation and concerning the interactions.

\section{References}

Abdel-Rahman, H.M. (1988) "Product differentiation, monopolistic competition and city size" Regional Science and Urban Economics 18 69-87.

Anas, A., R. Arnott and K. Small "Urban Spatial Structure" Journal of Economic Literature 36 14261464.

Arnott, R. (1979) "Optimal city size in a spatial economy" Journal of Urban Economics 6 65-89.

Atkinson, A.B. and J.E. Stiglitz (1980) Lectures on Public Economics McGraw-Hill, London.

Berk, P. and K. Sydsæter (1993) Economists' Mathematical Manual (second edition) Springer-Verlag, Berlin.

Camagni, R., R. Capello and P. Nijkamp (1998) "Sustainable city policy: economic, environmental, technological" Ecological Economics 24 103-118.

Chiang, A.C. (1984) Fundamental Methods of Mathematical Economics (third edition) McGraw-Hill, Auckland.

De Groot, H.L.F. (2000) Growth, Unemployment and Deindustrialisation Edward Elgar, Cheltenham.

Fujita, M. (1989) Urban Economic Theory: Land Use and City Size Cambridge University Press, Cambridge.

Fujita, M., P. Krugman and A.J. Venables (1999) The Spatial Economy: Cities, Regions and International Trade MIT, Cambridge.

Freeman, A.M. III (1993) "Property value models" in: The Measurement of Environmental and Resource Values: Theory and Methods Resources for the Future, Washington D.C., 367-420. 
Giuliano, G. and K.A. Small "Subcenters in the Los Angeles region" Regional Science and Urban Economics 21 163-182.

Glaeser, E.L. (1998) "Are cities dying?" Journal of Economic Perspectives 12 139-160.

Hamilton, B.W. (1975) "Zoning and property taxation in a system of local governments" Urban Studies 12 205-211.

Kanemoto, Y. (1976) "Optimum, market and second-best land use patterns in a von Thünen city with congestion" Regional Science and Urban Economics 6 23-32.

Kishimoto, K. (1991) "Coexistence and segregation of two groups in a metropolitan area through externalities" Journal of Urban Economics 30 293-309.

Nijkamp, P. (1999) "Environment and regional economics" in: J.C.J.M. van den Bergh (1999) Handbook of Environmental and Resource Economics Edward Elgar, Cheltenham, 525-538.

Oates, W.E. (1983) "The regulation of externalities: efficient behaviour by sources and victims" Public Finance 38 362-375.

Oron, Y., D. Pines and E. Sheshinski (1973) "Optimum vs. equilibrium land use pattern and congestion toll" Bell Journal of Economics and Management Science 4 619-636.

O'Sullivan, A (1996) Urban Economics (third edition) Irwin, Chicago.

Richardson, H.W. (1977) "On the possibility of a positive rent-gradient" Journal of Urban Economics 4 60-68.

Rose-Ackerman (1975) "Racism and urban structure" Journal of Urban Economics 2 85-103.

Solow, R.M. and W.S. Vickrey (1973) "Land use in a long narrow city" Journal of Economic Theory 3 430-447.

Sullivan, A.M. (1986) "A general equilibrium model with agglomerative economies and decentralized employment" Journal of Urban Economics 20 55-74.

Tauchen, H. (1981) "The possibility of positive rent gradients reconsidered" Journal of Urban Economics 9 165-172.

Tiebout, C.M. (1956) "A pure theory of local expenditures" Journal of Political Economy 64 416-424.

Varian, H.R. (1992) Microeconomic Analysis (third edition) Norton, New York.

Verhoef, E.T. (1994) "Efficiency and equity in externalities: a partial equilibrium analysis" Environment and Planning 26A 361-382.

Verhoef, E.T. and P. Nijkamp (1998) "Spatial dimensions of environmental policies for trans-boundary externalities: a spatial price equilibrium approach" Discussion paper TI 98-079/3, Tinbergen Institute, Amsterdam-Rotterdam.

Yinger, J. (1992) "An analysis of the efficiency of urban spatial structure, with an application to racial integration" Journal of Urban Economics 31 388-407. 


\section{Appendix: derivations for the general model}

This appendix gives the full derivation of the results presented in Section 2. We start with the consumers, and then proceed with the firms. The derivations often follow, without further references being made, exposition given in standard texts such as Varian (1992), Chiang (1984), Berk and Sydsæter (1993) and Atkinson and Stiglitz (1980).

\section{A.1 Consumers}

For convenience of reference, we first repeat the main equations from the main text.

The consumers' optimization problem is:

$$
\begin{aligned}
& \underset{y(z), s(z), T_{f}(z)}{\operatorname{Max}} U\left(y(z), s(z), T_{f}(z), E q(z)\right) \\
& \text { s.t. } \frac{R}{N}+w \cdot\left(T-t \cdot z-T_{f}(z)\right)-p \cdot y(z)-r(z) \cdot s(z)=0
\end{aligned}
$$

The gross budget available at location $\mathrm{z}$ is defined as:

$$
M(z)=\frac{R}{N}+w \cdot(T-t \cdot z)
$$

The Cobb-Douglas utility function is:

$$
U(z)=y(z)^{\alpha_{y}} \cdot s(z)^{\alpha_{s}} \cdot T_{f}(z)^{\alpha_{f}} \cdot E q(z)^{\alpha_{e}}
$$

with : $\alpha_{y}+\alpha_{s}+\alpha_{f}=1$

Equations (5abc), (6), (10) and (11) were presented without proof in the main text, and will be considered below. These equations state that the conditional demands for $\mathrm{y}, \mathrm{s}$ and $\mathrm{T}_{\mathrm{f}}$ are:

$$
\begin{aligned}
& y(z)=\frac{\alpha_{y} \cdot M(z)}{p} \\
& s(z)=\frac{\alpha_{s} \cdot M(z)}{r(z)} \\
& T_{f}(z)=\frac{\alpha_{f} \cdot M(z)}{w}
\end{aligned}
$$

that the indirect utility can be written as:

$$
\begin{aligned}
V(z) & =\alpha_{y} \cdot \ln \alpha_{y}+\alpha_{s} \cdot \ln \alpha_{s}+\alpha_{f} \cdot \ln \alpha_{f}+\ln \left(\frac{R}{N}+w \cdot(T-t \cdot z)\right) \\
& -\alpha_{y} \cdot \ln p-\alpha_{s} \cdot \ln r(z)-\alpha_{f} \cdot \ln w+\alpha_{e} \cdot \ln E q(z)
\end{aligned}
$$

that the condition that $\mathrm{V}$ in (6) be constant over place implies:

$$
V^{\prime}(z)=\frac{-w \cdot t}{\frac{R}{N}+w \cdot(T-t \cdot z)}-\alpha_{s} \cdot \frac{r^{\prime}(z)}{r(z)}+\alpha_{e} \cdot \frac{E q^{\prime}(z)}{E q(z)}=0
$$

and that (10) leads to an equilibrium pattern of land rents of: 
$r(z)=\left(\frac{\left(\frac{R}{N}+w \cdot(T-t \cdot z)\right) \cdot E q(z)^{\alpha_{e}}}{K}\right)^{\frac{1}{\alpha_{s}}}$

where $\mathrm{K}$ is a constant of integration.

As stated, equations (5abc), (6), (10) and (11) above deserve some further elaboration here. The consumers' optimization problem considered in the main text can be simplified by observing that the maximization of the Cobb-Douglas utility function in (4) necessarily implies the maximization of the logarithm of this same utility function, and vice versa. Hence, the following Lagrangian represents this optimization problem:

$$
\begin{aligned}
\Lambda= & \alpha_{y} \cdot \ln y(z)+\alpha_{s} \cdot \ln s(z)+\alpha_{f} \cdot \ln T_{f}(z)+\alpha_{e} \cdot \ln E q(z) \\
& +\lambda \cdot\left(M(z)-w \cdot T_{f}(z)-p \cdot y(z)-r(z) \cdot s(z)\right)
\end{aligned}
$$

with $\mathrm{M}(\mathrm{z})$ as defined in (3) in the main text. The first-order conditions are:

$$
\begin{aligned}
& \frac{\partial \Lambda}{\partial y(z)}=\frac{\alpha_{y}}{y(z)}-\lambda \cdot p=0 \\
& \frac{\partial \Lambda}{\partial s(z)}=\frac{\alpha_{s}}{s(z)}-\lambda \cdot r(z)=0 \\
& \frac{\partial \Lambda}{\partial T_{f}(z)}=\frac{\alpha_{f}}{T_{f}(z)}-\lambda \cdot w=0 \\
& \frac{\partial \Lambda}{\partial \lambda}=M(z)-w \cdot T_{f}(z)-p \cdot y(z)-r(z) \cdot s(z)=0
\end{aligned}
$$

Using $\alpha_{\mathrm{y}}+\alpha_{\mathrm{s}}+\alpha_{\mathrm{f}}=1$, substitution of (A.2)-(A.4) into (A.5) yield that $\lambda=1 / \mathrm{M}(\mathrm{z})$. After this, equations (5a)-(5c) in the main text follow directly from (A.2)-(A.4). Substitution of the conditional demands in (5a)-(5c) into the logarithm of utility (the objective in (A.1)) immediately yields the indirect utility function given in (6).

The equilibrium pattern of land rents for which utility is constant over space, given in equation (11), can most easily be verified as follows. First, determine the space derivative of (11) as:

$$
\begin{aligned}
r^{\prime}(z)= & \frac{1}{\alpha_{s}} \cdot\left(\frac{\left(\frac{R}{N}+w \cdot(T-t \cdot z)\right) \cdot E q(z)^{\alpha_{e}}}{K}\right)^{\frac{1}{\alpha_{s}}-1} \\
& \cdot \frac{-w \cdot t \cdot E q(z)^{\alpha_{e}}+\left(\frac{R}{N}+w \cdot(T-t \cdot z)\right) \cdot \alpha_{e} \cdot E q(z)^{\alpha_{e}-1} \cdot E q^{\prime}(z)}{K}
\end{aligned}
$$

One can then write the second term in the middle expression of (10) as: 


$$
\begin{aligned}
\alpha_{s} \cdot \frac{r^{\prime}(z)}{r(z)} & =\left(\frac{\left(\frac{R}{N}+w \cdot(T-t \cdot z)\right) \cdot E q(z)^{\alpha_{e}}}{K}\right)^{-1} \\
& \cdot\left(\frac{-w \cdot t \cdot E q(z)^{\alpha_{e}}}{K}+\frac{\left(\frac{R}{N}+w \cdot(T-t \cdot z)\right) \cdot \alpha_{e} \cdot E q(z)^{\alpha_{e}-1} \cdot E q^{\prime}(z)}{K}\right) \\
& =\frac{-w \cdot t}{\frac{R}{N}+w \cdot(T-t \cdot z)}+\alpha_{e} \cdot E q(z)^{-1} \cdot E q^{\prime}(z)
\end{aligned}
$$

Substitution of (A.7) into (10) in the main text shows that the pattern of land rents in (11) therefore satisfy the constant utility condition in (10). In other words, (11) is the solution to the differential equation in (10).

\section{A.2 Firms}

Equation (19) specifies the following CES production function:

$$
Q=A \cdot\left(\left(\delta_{L} \cdot L\right)^{\rho}+\left(\delta_{E} \cdot E n\right)^{\rho}\right)^{\frac{1}{\rho}}
$$

With A treated parametrically by firms, this production function exhibits constant returns to scale - which can be verified directly in (19) by checking that a simultaneous proportional increase in all inputs leads to a the same proportional increase in $\mathrm{Q}$, and also follows from the cost function derived in (A.18) below. The production function is homothetic - see also equations (A.15) and (A.16) below. We can thus solve the cost minimization problem at any possible scale level, and should find the same production costs and conditional input demands per unit of product. Considering the aggregate production level, the cost minimization problem can be represented by the following Lagrangian:

$$
\Lambda=w \cdot L+p_{E} \cdot E n+\lambda \cdot\left(\left(\frac{Q}{A}\right)^{\rho}-\left(\left(\delta_{L} \cdot L\right)^{\rho}+\left(\delta_{E} \cdot E n\right)^{\rho}\right)\right)
$$

The first-order conditions are:

$$
\begin{aligned}
& \frac{\partial \Lambda}{\partial L}=w-\lambda \cdot \rho \cdot \delta_{L} \cdot\left(\delta_{L} \cdot L\right)^{\rho-1}=0 \\
& \frac{\partial \Lambda}{\partial E n}=p_{E}-\lambda \cdot \rho \cdot \delta_{E} \cdot\left(\delta_{E} \cdot E n\right)^{\rho-1}=0 \\
& \frac{\partial \Lambda}{\partial \lambda}=\left(\frac{Q}{A}\right)^{\rho}-\left(\left(\delta_{L} \cdot L\right)^{\rho}+\left(\delta_{E} \cdot E n\right)^{\rho}\right)=0
\end{aligned}
$$

Recalling the definition $r=\rho /(\rho-1)$, we can rewrite (A.9) and (A.10) as:

$$
\left(\delta_{L} \cdot L\right)^{\rho}=\left(\frac{w}{\delta_{L}}\right)^{r} \cdot(\lambda \cdot \rho)^{-r}
$$


$\left(\delta_{E} \cdot E n\right)^{\rho}=\left(\frac{p_{E}}{\delta_{E}}\right)^{r} \cdot(\lambda \cdot \rho)^{-r}$

Substitution of (A.12) and (A.13) into (A.11) yields:

$$
(\lambda \cdot \rho)^{-r}=\left(\frac{Q}{A}\right)^{\rho} \cdot\left(\left(\frac{w}{\delta_{L}}\right)^{r}+\left(\frac{p_{E}}{\delta_{E}}\right)^{r}\right)^{-1}
$$

Substituting (A.14) back into (A.12) and (A.13), the following conditional factor demands can be derived:

$$
\begin{aligned}
& L=w^{r-1} \cdot \delta_{L}^{-r} \cdot\left(\left(\frac{w}{\delta_{L}}\right)^{r}+\left(\frac{p_{E}}{\delta_{E}}\right)^{r}\right)^{-\frac{1}{\rho}} \cdot\left(\frac{Q}{A}\right) \\
& E n=p_{E}^{r-1} \cdot \delta_{E}^{-r} \cdot\left(\left(\frac{w}{\delta_{L}}\right)^{r}+\left(\frac{p_{E}}{\delta_{E}}\right)^{r}\right)^{-\frac{1}{\rho}} \cdot\left(\frac{Q}{A}\right)
\end{aligned}
$$

From (A.15) and (A.16), we can directly derive the cost minimizing input ratio given in (21) in the main text:

$$
E n=L \cdot \frac{p_{E}^{r-1} \cdot \delta_{E}^{-r}}{w^{r-1} \cdot \delta_{L}^{-r}}
$$

After multiplication of (A.15) by w, and of (A.16) by $p_{E}$, it is finally straightforward to write the total production cost as:

$$
C=\left(\left(\frac{w}{\delta_{L}}\right)^{r}+\left(\frac{p_{E}}{\delta_{E}}\right)^{r}\right)^{\frac{1}{r}} \cdot\left(\frac{Q}{A}\right)
$$

which in turn directly implies the average production costs shown in (22):

$$
A C=\frac{1}{A} \cdot\left(\left(\frac{w}{\delta_{L}}\right)^{r}+\left(\frac{p_{E}}{\delta_{E}}\right)^{r}\right)^{\frac{1}{r}}
$$

